\title{
A proposed conceptualization of therapeutic competence: the three level model
}

\author{
Christine Koddebusch, Christiane Hermann \\ Department of Clinical Psychology and Psychotherapy, Justus Liebig University Giessen, Germany
}

\begin{abstract}
A model of therapeutic competence that equally satisfies the requirements of practice and research is still lacking. The existing models are not widely accepted, at least partially because the postulated competences can often not be operationalized in a satisfactory manner. Yet, in order to be measurable, therapeutic competences need to be operationalized. We present the Three Level Model of Therapeutic Competence as a working model for studying therapeutic competence. The model proposes that therapeutic competence develops based on rather stable individual Dispositions, which promote the acquisition of therapeutic competences. We further distinguish between Basic Competences, which are mostly independent of the theoretical orientation of the therapeutic approach, and Specific Competences, which are defined based on the theoretical underpinnings of a therapeutic orientation (e.g. Cognitive Behavioral Therapy). We describe this model and outline how it can be used to operationalize and assess therapeutic competence.
\end{abstract}

Key words: Therapeutic competence; Conceptualization; Operationalization; Dispositions; Research.

\section{Introduction}

What is a good therapist? Over the years, numerous efforts have been made to answer this question and to identify core therapeutic competences (Fouad et al., 2009; Guy, 1987; Purton, 1991; Rogers, 1957; Schaffer, Rodolfa, Hatcher, \& Fouad, 2013). Despite this long research tradition, interest has subsided in the meantime and investigation in treatment models, intervention and outcome became more popular (Baldwin \& Imel, 2013; Barkham, Lutz,

\footnotetext{
Correspondence: Christine Koddebusch, Justus Liebig University Giessen, Department of Clinical Psychology and Psychotherapy, Otto-Behaghel-Strasse 10F, D-35394 Giessen, Germany.

Tel.: +49.641.99.260.85 - Fax: +49.641.99.260.99.

E-mail: Christine.Koddebusch@psychol.uni-giessen.de

Contributions: the authors contributed equally.

Conflict of interest: the authors declare no potential conflict of interest.

Funding: The authors report grants from German Federal Ministry of Education and Research (BMBF) [01PL17035], during the conduct of the study.

Received for publication: 3 August 2017.

Revision received: 22 December 2017.

Accepted for publication: 27 December 2017.

This work is licensed under a Creative Commons Attribution NonCommercial 4.0 License (CC BY-NC 4.0).

CCopyright C. Koddebusch and C. Hermann, 2018

Licensee PAGEPress, Italy

Research in Psychotherapy:

Psychopathology, Process and Outcome 2018; 21:12-23

doi:10.4081/ripppo.2018.286
}

Lambert, \& Saxon, 2017). Therefore, the person of the therapist became for some time an almost neglected variable in psychotherapy research (Bergin, 1997).

Nevertheless, understanding therapist's role in the therapeutic process requires a consensus-based definition as well as a generally accepted model of therapeutic competence. The approach to find a general accepted definition can be drawn on the work by Kaslow (2004). Following Kaslow (2004), competence is defined as an individual's capability and demonstrated ability to understand and do certain tasks in an appropriate and effective manner consistent with the expectations for a person qualified by education and training in a particular profession or specialty thereof (p. 775). In addition, Barber, Sharpless, Klostermann, and McCarthy (2007) adapted a definition from the field of medicine (Epstein \& Hundert, 2002) on professional clinical psychology: competence can be thought of as the judicious application of communication, knowledge, technical skills, clinical reasoning, emotions, values, and contextual understanding for the benefit of the individual [...] being served (p. 494). While competence is understood as overall professional ability, the term competency describes single components of the performance. Accordingly, competencies are elements of competence (Kaslow et al., 2004) and are further defined as involving the whole person and being teachable, observable, measurable, containable, practical, derived by experts, flexible and transferable across settings, and continually reevaluated and redefined (Rubin et al., 2007, p. 453).

Besides a uniform definition, the investigation of therapeutic competence requires also a theoretical model. There is an ongoing debate about the question which therapeutic competences are central, especially in the area of Cognitive Behavioral Therapy [Cognitive Behavioral 
Therapy (CBT)] a generally accepted model is still lacking. A model of competence with a minimum of acceptance among researchers and clinicians is needed in order to allow measurement, to provide a framework of training and to possibly guide clinical practice. The lack of a consensus model is considered as a risk for science and practice of professional psychotherapy (Rodolfa et al., 2013), especially because quality management is difficult and in fact impossible. Yet, it is a challenge to define therapeutic skills such that they are theoretically satisfying, but also allow operationalization (Schaffer et al., 2013). Furthermore, the existing differences in theoretical orientations as well as national characteristics in training and licensure of psychotherapists also hinder reaching a consensus.

Most existing models of therapeutic competence can be subdivided depending on their focus. First, there are models elaborating the interaction between client and therapist within the therapeutic process. Examples are the experiential learning model of therapy process (Milne, Claydon, Blackburn, James, \& Sheikh, 2001) or the generic model of psychotherapy by Orlinsky and Howard (1987). Second, other models focus on the acquisition of therapeutic competences. Examples are the declarative, procedural and reflective systems model (DPR-Model) of therapeutic skill development by Bennett-Levy (2006) or the phases of therapists and counselors development over the life span by Rønnestad and Skovholt (2013). Such acquisition models usually do not directly entail a competence perspective. Instead, they focus on the inner experience of the therapist in different phases of one's development as a professional. Third, some models of therapeutic competences describe the training of professional psychologists in general (Cube Model by Rodolfa et al., 2005; Rodolfa et al., 2013) or of psychotherapists in particular (Three-Stages Model by Hill, 2009). Those training models in most cases refer primarily to the training period starting with the beginning of therapeutic work and ending when the academic training is completed (e.g. licensure) or shortly thereafter.

Finally, Roth and Pilling (2007) published a competence framework as part of the British Improving access to Psychological Therapy (IAPT) program. Their map of CBT competences contains of generic therapeutic competences that are independent of the theoretical orientation of the psychotherapists as well as domains of specific competences that are formulated for CBT, for Psychoanalytic/Psychodynamic Therapy (Lemma, Roth, \& Pilling, 2008) as well as for other theoretical orientation of psychotherapy and counseling.

All in all, the existing models of therapeutic competence have certain limitations. First, models developed for the training context are limited to the stages of the formal training. One may question whether such formal training stages (e.g. practicum, internship) describe the acquisition of therapeutic competences adequately. Indeed, these stages are not compatible with the acquisition of compe- tences outlined by respective models such as the phases of professional development formulated by Rønnestad and Skovholt (2013). Accordingly, target skills for training are defined, but qualitative aspects of the acquisition of a competence are not outlined. Furthermore, although it is generally agreed upon that the gain in competence does not end with licensure but continues over the professional life-span, most competence models are formulated within the context of academic psychology and training and therefore end with licensure (Rodolfa et al., 2013).

Besides, authors used different strategies for identifying key competences. As an example, Roth and Pilling (2007) focused on outcome research and reviewed the outcome literature for identifying effective manuals of psychological approaches and extracted the associated competences. Similarly, many authors studied therapeutic competence within the context of outcome (see Heinonen, Knekt, Jääskeläinen, \& Lindfors, 2014; Hill et al., 2008). Yet, therapy outcome studies are not designed to explore the influence of therapists' individual characteristics on the acquisition and development of therapeutic competence. Furthermore, outcome is influenced by many circumstances beside the competence of the therapist (James, Blackburn, Milne, \& Reichfelt, 2001). The simple interpretation of the total correlation between therapists' variables and outcome is an oversimplification because not considering the level of analysis. Moreover, variability in therapists' variables are due to the patient and/or to the therapist (Wampold, Baldwin, Grosse Holtforth, \& Imel, 2017). Therefore, any inferences about therapeutic competences driven from analyses of theses total correlations must be treated with caution. Nonetheless, results from outcome studies might provide first clues which competences are relevant.

Furthermore, practical usability of some models must be questioned. Sometimes, the behavioral examples entail rather broad and abstract descriptions of a therapist's behavior and seem to have been derived in many cases without reliance on empirical findings. Beyond that, a clear operationalization is mostly lacking. In consequence, the use for within-session assessment of therapeutic competence is complicated. Moreover, competences and associated behavioral examples appear already quite complex for the first phase of professional development called as novices student phase (Rønnestad \& Skovholt, 2013). In consequence, they do not seem to be applicable for beginner therapists in the pre-training phase (Skovholt, 2012) prior to professional training. Furthermore, Sharpless and Barber (2009) asked for teaching those competences to students that have been demonstrated to be teachable. The existing models do not differentiate between therapeutic skills that may be easier to train and learn as opposed to other domains that may more strongly reflect a person's dispositions. Similarly, the existing models do not specifically take into consideration that the acquisition of therapeutic compe- 
tence may also be influenced by the therapist's individual characteristics.

All in all, a theoretical model of therapeutic competence is needed, that allows multi-method and multi-informant operationalization for assessment (Hatcher et al., 2013; Kaslow, 2004), with high practicability and applicability to initial stages of clinical training.

We propose a new conceptualization of therapeutic competence. This working model is conceptualized such that it is empirically testable and, for the purpose of assessment, allows an operationalization of the defined competences. Also, it aims to facilitate a multimodal assessment of therapeutic competence by therapists, clients and non-participant observers. Furthermore, it is applicable for within-session assessment of therapeutic competence in initial stages of clinical training. The model further aims at providing a framework for the analysis of the developmental process including the consideration of individual traits that may or may not foster the competence development. Finally, the model takes into account that therapeutic competence is not exclusively defined based on a specific therapeutic approach. In the following, the Three Level Model will be described as a working model for investigating therapeutic competence in the field of CBT. For identifying the competences, we combined a theoretical and an empirical research-driven approach. Accordingly, we reviewed theoretical essays from the last decades as well as therapeutic outcome literature.

In the following the Three Level Model of Therapeutic Competences will be presented in detail.

\section{The three level model of therapeutic competence}

We propose a Three Level Model of Therapeutic Competence as a heuristic framework for investigating therapeutic competence and its dispositions (Figure 1).

The Three Level Model proposes that therapeutic competence develops and can be trained, but also takes into account individual Dispositions which are postulated to be the basis for the acquisition of therapeutic competences. We further distinguish between Basic Competencies, which are mostly independent of the theoretical orientation, and Specific Competencies, which differ depending on the theoretical orientation. Here we refer to competences relevant in CBT.

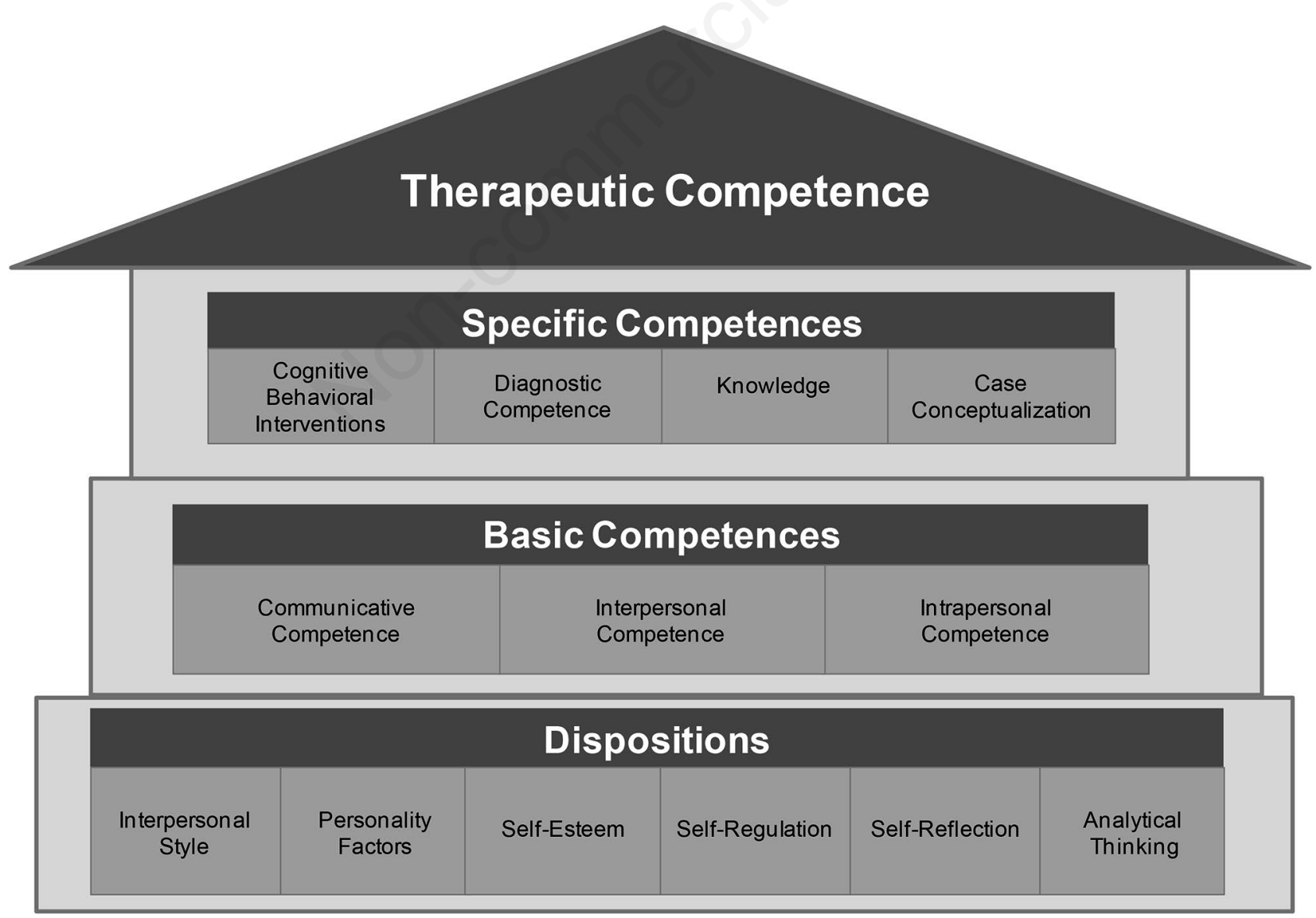

Figure 1. The Three Level Model of Therapeutic Competence within a cognitive-behavioral framework. 


\section{Individual dispositions as the basis of therapeutic competence}

During the last decades, dating back to the 1980s, therapists individual dispositions were investigated in terms of their predictive value (Costanzo \& Philpott, 1986; Guy, 1987). Findings were often inconsistent and lacked robustness, and finally research on the therapist as a person declined (Beutler, Machado, \& Neufeldt, 1994; Caspar \& Eversmann, 2009). As a consequence, theoretical accounts about potentially more or less favorable individual characteristics of therapists' are still rather vague. Concerning the finding that some therapists are consistently more successful than others (Wampold et al., 2017), the discussion about what characterizes this exceptional therapists goes on and brings new power to the topic of therapists characteristics.

Although the lack of consideration of beneficial and malign characteristics (Aveline, 2005, p. 155) has been widely criticized (Ackerman \& Hilsenroth, 2001; Aveline, 2005; Bergin, 1997), dispositions find little consideration in current models of therapeutic competence. An exception is the aspect interpersonal behavior of the therapist that is considered in the Social Competencies in Interpersonal Process (SCIP) Model by Mallinckrodt (2000). The SCIP model focuses on the contribution of therapists' social competencies and dispositions to the therapeutic process (Mallinckrodt, 2000, p. 241). In a similar vein, Hatcher and Lassiter (2007) emphasized the importance of personality characteristics and intellectual and personal skills that students bring with them to professional training. Accordingly, they specify several interpersonal, cognitive and reflective skills such as the ability to listen and be empathic and respectful of others...critical thinking...[and] the ability to examine and consider one's own motives, attitudes and behaviors (Hatcher \& Lassiter, 2007, p. 60). All in all, Schmelzer (1997) concluded that the catalogue of therapists' personal characteristics represents mostly a collection of socially desirable personality traits. Overall, current models regarding therapeutic competencies outline the role of dispositional factors only tentatively or not at all. To what extent such individual traits may influence the training and acquisition of therapeutic competency is often not specified and, therefore, research is lacking. In order to enable empirical research, Dispositions should be included in theoretical models of central therapeutic competences. That therapists' interpersonal skills are discussed as central in the research about exceptional therapists (Barkham et al., 2017) is further evidence of this approach.

Much of what we know about the predictive value of certain therapists' characteristics for therapeutic competence comes from older studies (Costanzo \& Philpott, 1986; Guy, 1987; Loo, 1979; Purton, 1991), which, due to methodological problems like absence of psychomet- rical validation of the used assessment methods or only indirect assessment of therapeutic competence via essays or role-plays, only allow rather limited conclusions. Furthermore, these earlier studies have focused mostly on aspects such as the academic performance and interpersonal interaction style as potential predictors. By contrast, other possible predictors like self-esteem have not been systematically investigated. Other studies investigated relevant dispositions based on results of outcome studies. For example, in a study on the outcome of patients suffering from various mental disorders, therapists' professional self-doubt was positively associated with outcome (Nissen-Lie, Monsen, Ulleberg, \& Rønnestad, 2013). However, it must be noticed that the study included primarily psychoanalytic/psychodynamic therapist, only one-third of the participants reported a mainly cognitive orientation. The theoretical orientation of the investigated sample might have had an influence on the reported results. Nevertheless, such self-doubting is possibly influenced by dispositional self-reflection. Similarly, hostility has been shown to be negatively related to outcome (Henry, Schacht, \& Strupp, 1986, 1990) and as a trait may constitute a disposition that negatively impacts therapeutic competence. The limitations of findings driven from outcome studies are already discussed above. Wampold et al. (2017) call for a differentiation between therapists' action and the personal characteristics he already brings to the therapy for understanding the beneficial therapists' variables. In our understanding, the inclusion of individual Dispositions in a model of therapeutic competence as a separate level is a further necessary step in promoting research in this area.

We define Dispositions as therapists' individual characteristics that already present prior to the professional training and/or work as a therapist. We postulate interpersonal style, personality factors, self-esteem, self-regulation, self-reflection and analytical thinking as central characteristics. Dispositions are presumed to be less malleable or even trainable. Importantly, however, we postulate that they effect the acquisition of therapeutic competences. Depending on therapists' individual characteristics, the difficulty of training might differ and as well the competence level that may be achieved.

The level Dispositions of the Three Level Model consists of six components that will be addressed in the following in more detail.

\section{Interpersonal style}

Some models of therapeutic competence like the SCIP model (Mallinckrodt, 2000) consider the aspect of the therapist's interpersonal behaviour. While Mallinckrodt (2000) clearly regards this as a disposition, other models like the US Benchmark Model (Fouad et al., 2009) do not differentiate strictly between interpersonal behavior as a dispositional trait versus a therapeutic competence. Accordingly, descriptions of beneficial interpersonal behavior are often 
global and unspecific like maintains satisfactory interpersonal relationships with clients (Fouad et al., 2009, p. 12). Operational definitions of appropriate interpersonal competence are often lacking, thus making the assessment quite challenging. The role of therapists' interpersonal style has mostly been studied within the context of therapeutic outcome. For example, Benjamin's (1974) structural analysis of social behavior (SASB) model has been used to elucidate this relationship. Hostile, belittling and blaming behaviors of the therapist were found to be associated with less successful therapies (Henry et al., 1986, 1990). In sum, however, our knowledge of beneficial (or maleficent) interaction behavior of therapists is quite limited. Moreover, there is little consensus which interaction behaviors are helpful or not helpful. A good example is the behavior style dominance. Some researchers advocate less dominance as positive (Beutler et al., 1994), others question a purported detrimental influence of therapist's dominance. Specifically, therapeutic outcome may be enhanced by a more dominant behavioral style of the therapist because the patient may feel safer (Engvik, 1999).

We suggest that interpersonal style refers to an adequate interpersonal behavior, this means a person can adjust their interpersonal behavior depending on the counterparts' feelings and is able to engage in positive interpersonal interactions. The interaction style is cooperative and open (Purton, 1991) and not characterized by craving for power or recognition and by a desire to control (Dobson \& Shaw, 1993; Guy, 1987) or by hostility (Dobson \& Shaw, 1993; Henry et al., 1986). While dominance may be sensitive to change by training, we assume that other facets of interpersonal style are less malleable by training (e.g. caring attitude or dependability).

\section{Personality factors}

Beutler et al. (1994) is one of very few researchers who explicitly referred to personality as a relevant trait contributing to therapeutic competence. Unfortunately, the role of therapists' personality in regard to therapeutic competence has rarely been explored (Baldwin \& Imel, 2013). Conclusions are difficult to draw given that there are few findings and that the obtained effects seem small and even heterogeneous (Antonuccio, Lewinsohn, \& Steinmetz, 1982; Beutler et al., 1994). Based on the Big Five (McCrae \& John, 1992), agreeableness, conscientiousness, low levels of neuroticism, and a moderate degree of extraversion have been for example proposed as beneficial characteristics of a therapist (Engvik, 1999). In Engvik's study (1999), students were asked whom of their fellow students they would choose as therapist. These individuals' preferences were related to the personality of the chosen therapist, as rated by peers. Clearly, one may argue that these individual preferences primarily reflect a person's popularity and the social desirability of certain personality traits rather than actual interpersonal style. Other authors also emphasize the relevance of openness to experiences for therapeutic work (Doering-Seipel, Schüler, \& Seipel, 2000).

In line with these findings, we suggest that high agreeableness, high conscientiousness, high openness to experiences, low to moderate neuroticism and moderate extraversion are beneficial personality traits that, in and by themselves, are relevant for the acquisition of therapeutic competence by hindering or facilitating it (Doering-Seipel et al., 2000; Engvik, 1999).

\section{Self-esteem}

Therapist's self-esteem is less considered in models of therapeutic competence and is accordingly little explored. There are some research findings that clients of therapists with higher self-confidence benefit more from the therapy (Williams \& Chambless, 1990). Though, Williams and Chambless (1990) refer to clients' prospective ratings of therapists' characteristics. Although findings regarding therapists' self-esteem are inconsistent, they suggest that low self-confidence is an unfavorable characteristic of psychotherapists (Beutler et al., 2004).

In our model, we refer to self-esteem primarily as the emotional component of a person's self-concept. Putatively, an adequately (but not excessively) high positive self-esteem and a concomitant absence of severe selfdoubts are beneficial dispositions for acquiring therapeutic competence.

\section{Self-regulation}

As self-regulation, we summarize self-efficacy, emotion regulation and self-care. Self-efficacy describes an individual's expectation that a situation is manageable by one's own resources and competences (Bandura, 1977), in addition, a distinction is made between general and more behavior-related (e.g. occupational) self-efficacy. We know no model of therapeutic competence that explicitly includes therapists' self-efficacy as disposition for therapeutic competence, accordingly there is less research on its impact on therapeutic competence. However, occupational self-efficacy has been investigated in counseling. In these studies, occupational self-efficacy correlated positively with performance and counselors' satisfaction and negatively with anxiety during counseling (Larson \& Daniels, 1998; Lent, Hill, \& Hoffman, 2003). Considering theories of general self-efficacy, self-efficacy is amongst other factors associated with higher staying power, higher thoroughness and less anxiety for difficult tasks and more physical and mental health (Aronson, Wilson, \& Akert, 2002). At least some of these aspects might be of relevance for the development of therapeutic competence. Possibly, these aspects are also relevant and beneficial for the acquisition of therapeutic competence and for psychotherapists in general. Hence, higher perceived self-efficacy regarding to the optimistic estimation of general life coping strategies may be an important beneficial disposition for therapeutic competence. 
Emotion regulation refers to the therapists' strategies to influence their own experience of emotions. The ability to influence one's own emotional state has been considered as a beneficial therapeutic characteristic because it promotes therapists' emotional stability (Beutler et al., 2004; Strauss \& Kohl, 2009). Adequate emotion regulation has even been discussed as a criterion for selecting candidates for psychotherapy training (Purton, 1991). Other models postulate that emotion regulation constitutes a therapeutic competence primarily relevant for handling emotional topics during session (Roth \& Pilling, 2007).

We understand emotion regulation as the ability to modulate the emotional experience by emotional regulation strategies (e.g. acceptance or refocusing) and thereby controlling and positively influencing its intensity, length and expression. In our model, emotion regulation is a dispositional trait contributing to therapeutic competence: therapists' own emotional stability and, concomitantly, not being overwhelmed by own feelings are the basis for responding professionally (i.e. empathically and sensitively) to the needs of the patient.

Self-care describes therapists' individual strategies (such as optimism, vitality and positive mood) to restore and conserve one's own personal resources and to maintain emotional stability for preventing distress by integrating self-care strategies into everyday life (Wise, Hersh, \& Gibson, 2012). In contrast to the previous disposition emotion regulation, self-care relates to specific behaviors and includes activities like exercising, reading or traveling, but also includes spiritual activities such as religious exercises (e.g. praying) or meditation (Mahoney, 1997; Wise et al., 2012). Emotional well-being is closely related to ongoing self-care and, as such, has already been suggested by Beutler et al. (1994) as a pertinent therapist characteristics. The importance of psychotherapists' self-care (Elman, IllfelderKaye, \& Robiner, 2005; Norcross, 2000; Wise et al., 2012), and especially potential difficulties in engaging in self-care has been addressed by many experts in the field (Figley, 2002). Wise et al. (2012) emphasize the interplay between care of the self and care of the other (p. 488). Although there are some approaches for ensuring therapists' well-being by methods of self-care (Norcross \& Guy, 2007), there is surprisingly little empirical evidence that demonstrates the relevance of self-care as a therapeutic competence.

We define self-care as those individual strategies which a therapist relies on for promoting their own emotional well-being. This component includes one's ability to get one's mind off the job, to relax without thinking about work as well as knowing and performing activities to switch off and recover.

\section{Self-reflection}

Self-reflection can be defined as the observation, interpretation and evaluation of one's own thoughts, emotions and actions, and their outcomes (Bennett-Levy, 2006, p. 60 ). Therapist ability to self-reflect is often listed as a fa- vorable therapist characteristic (Dryden \& Feltham, 1994; Guy, 1987) and reflection is postulated as key competence for the development of expertise in the models by BennettLevy (2006) and Skovholt and Rønnestad (1992). Furthermore, the US competency models entail reflective practice as a relevant competence (Hatcher et al., 2013; Rodolfa et al., 2005). Although self-reflection has also been proposed as a selection criterion for candidates (Purton, 1991), there is no empirical research on this subject known to us. One of the main reasons for this is most likely the difficulty to operationalize this competence and accordingly the lack of appropriate assessment instruments.

We define self-reflection as mental self-observation of one's own thoughts, emotions and actions during and after a certain situation or directed on the future (Dauber, 2006). The therapist is able to observe their own behavior, to think without prejudices from different perspectives, and to accept and reflect criticism (Dryden \& Feltham, 1994). Furthermore, self-reflection is the basis that enables therapists to make selective decisions about the appropriate use of certain interventions (Bennett-Levy, 2006).

\section{Analytical thinking}

Models of therapeutic competence and theoretical elaborations on key competences differ in how they construe the role of the therapist's intellectual ability. Some authors suggest that therapeutic competence is unrelated to intellectual abilities as inferred from academic performance (Carkhuff, 1969). Consistent with this line of thinking, current grade-point average did not predict the success of college students participating in a counseling training for improving helping-skills (Hill et al., 2008). This finding might be limited by the fact that competence was only rated by counselors, clients and in addition derived from counselors' verbal behavior, but there was no rating by an external observer. In contrast, intellectual ability has been proposed as a prerequisite, and accordingly as a selection criterion (Dobson \& Shaw, 1993; Dryden \& Feltham, 1994; Purton, 1991). Indeed, intellectual ability has been conceptualized as a part of thinking like a psychologist (Elman et al., 2005, p. 369) with a particular emphasis on critical and logical thinking. In addition, Hatcher and Lassiter (2007) emphasize cognitive skills as one of the intellectual abilities a trainee must bring to graduate training. It should be noted that, at least implicitly, analytical thinking is implemented as a selection criterion for psychotherapy students in many countries (e.g., USA, Germany, Netherlands) due to the fact that admission to training programs in clinical psychology is highly competitive with academic performance often being the most crucial requirement. As a consequence, psychotherapy students are quite likely to be rather homogenous which could obscure the actual influence of analytical thinking. Possibly, there is a benefit of intellectual ability in accounting for therapeutic competence initially, which may dissipate over the course of training (Costanzo \& Philpott, 1986). 
We conceptualize analytical thinking as the ability to take the meta-perspective by abstracting, reasoning and recognizing rules and principles toward developing an appropriate case formulation and treatment plan as well as adjusting the latter in an ongoing manner.

\section{Level basic competences}

The second level Basic Competences represents competencies, which are postulated to be basic skills for working as a therapist. They are conceptualized as universal regardless of the theoretical therapeutic approach. Communicative competence, interpersonal competence and intrapersonal competence are postulated to be teachable components of therapeutic competence.

\section{Communicative competence}

The first component communicative competence comprises key elements of therapeutic communication like empathy, beneficial basic attitude and several basic communication competences. Empathy is indisputably a key element of therapeutic competence (Dobson \& Shaw, 1993; Guy, 1987) and its relation to therapy outcome has been discussed intensively (Greenberg, Watson, Elliott, \& Bohart, 2001). In fact, there seems to be a moderate correlation between empathy and therapy success (Elliott, Bohart, Watson, \& Greenberg, 2011). Whether empathy is teachable or not, is a matter of controversy (Hill \& Lent, 2006). By conceptualizing empathy as a Basic Competence, we share the view that empathy is teachable - at least to some extent. Within the context of client centered therapy (Rogers, 1957), empathy has been defined as the understanding of the emotional connotation in addition to mere content. The therapist is able to develop and show both an emotional and cognitive understanding of clients' assumed emotional state (Thwaites \& Bennett-Levy, 2007) and to take on the clients' perspective and their individual system of thoughts and personal values. Being a rather broad category, communicative competence also encompass other aspects of therapists' basic attitudes such as genuineness and positive regard for which recent studies had shown moderate associations with therapeutic outcome (Farber \& Doolin, 2011; Kolden, Klein, Wang, \& Austin, 2011). Similarly, the personality of the therapist has been supposed to be characterized by warmth, caring, kindness and trustworthiness (Ackerman \& Hilsenroth, 2003; Guy, 1987). Finally, communicative competence also entails basic communication skills like active listening, the art of questioning and guided discovery (Guy, 1987; Newman, 2010; Rogers, 1957; Roth \& Pilling, 2007).

\section{Interpersonal competence}

This competence denotes both the establishment and maintenance of a working alliance, but also the adequate role behavior of the therapist including a confident professional appearance. These aspects were summarized as interpersonal competence because they focus on the interaction between therapist and client. Barkham et al. (2017) summarized current research and concluded that differences in therapists interpersonal skills might explain most of the variability in therapists outcomes.

The importance of a therapeutic alliance is highlighted in numerous models and theoretical considerations (Grawe, Donati, \& Bernauer, 1994; Horvath, Del Re, Flückiger, \& Symonds, 2011; Sudak, Beck, \& Wright, 2003). Most importantly, much research has been devoted to elucidating its influence on therapeutic outcome. Despite being somewhat heterogeneous, findings suggest that a good working alliance has a moderate sized favorable effect on patients' outcome (Horvath et al., 2011; Martin, Garske, \& Davis, 2000).

Aside from working alliance, interpersonal competence also refers to the therapist's ability to comply with the role of a professional therapist. Specifically, this concerns the optimal regulation of closeness and distance within the therapeutic setting (Langer \& Frank, 1999; Willutzki \& Laireiter, 2005). This aspect has received surprisingly little attention of researchers and, to the best of our knowledge, there are no international publications that address this aspect of competence. Also, an appropriate professional appearance is rarely mentioned in the literature. As an example, Leith, McNiece, and Fusilier (1989) see therapists' posture and clothes as an important part for conveying a professional and confident attitude to the clients (see also Hatcher \& Lassiter, 2007).

We postulate that therapists' competences to develop and maintain a therapeutic alliance as well as an adequate role behavior and professional appearance are essential facets of interpersonal competence.

\section{Intrapersonal competence}

Intrapersonal competence focuses on therapists' emotional security during sessions. Few models of therapeutic competence explicitly address therapists' emotional stability during a session. Yet, Roth and Pilling (2007) emphasize the relevance of the competence to handle the emotionality of sessions, the same did Langer and Frank (1999). In our working model this component covers the aspects sovereignty, which is expressed in a calm and clear voice and also relaxed posture. All in all, the therapist is not overtaxed with the contents of the session.

\section{Level specific competences}

Finally, we propose that Specific Competences contribute to therapeutic competence. Unlike Dispositions and Basic Competences, we further assume that these Specific Competences need to be defined depending on the 
theoretical assumptions of each therapeutic approach. Here, we outline Specific Competences within the context of CBT, and therefore specify the components cognitive behavioral interventions, diagnostic competence, knowledge and case conceptualization.

\section{Cognitive behavioral interventions}

This therapeutic competence refers to specific CBT competences which have already been proposed by previous models of therapeutic competences, though not necessarily all within one model (Hatcher et al., 2013; Rodolfa et al., 2013; Roth \& Pilling, 2007). Yet, how much of the variance in outcome is due to specific techniques is not entirely clear, but it seems to be a small percentage (Beutler et al., 2004; Wampold, 2001).

CBT represents a goal-oriented approach with a focus on problem solving and solution orientation (Grawe, 2007; Roth \& Pilling, 2007; Sudak et al., 2003). As such, CBT is explicitly resource-oriented (Duckworth, Steen, \& Seligman, 2005; Grawe, 2007). Thus, therapists need to have competences in resource activation such as recognizing and reinforcing clients' strengths, and supporting clients in engaging in resource-oriented behaviors. In addition, CBT relies on the active participation of the client. Accordingly, the therapist is supposed to encourage the client to take on an active role and to come up with own solutions, and at the same time to abstain from specific advice. In addition, in order to gain a better understanding of the patients' behavior and its determinants, the therapist encourages the client in reflecting own behavior. Hence, the therapist is required to nurture clients' self-management competences (Kanfer, 2006; Kanfer \& Schefft, 1988). To this end, the therapist should have expertise in conveying positive treatment expectations, what can be understand in terms of allegiance which was postulated by Wampold (2001) as a central factor for the efficacy of psychotherapy. Consistent with the underlying problemsolving approach, a CBT therapist should be competent at structuring the session. Formal structuring includes that the therapist plans a session as a sequence of different phases (warm-up, working, cool-down). Beyond the formal structure, the therapist needs to establish and pursue the focus of the session. Most models of therapeutic competence include the ability to structure a session (e.g. Roth \& Pilling, 2007; Sudak et al., 2003). Furthermore, the therapist needs to be able to recognize the emotional state of a client and flexibly adjust the session and own behavior. Our model does not explicitly list specific CBT techniques like cognitive restructuring, socratic questioning, behavioral activation, behavioral tests or exposure as these can be subsumed as problem-specific competences (Roth \& Pilling, 2007). We believe that a model of therapeutic competence needs to be parsimonious and, therefore, should primarily define broader categories of competences rather than building upon more or less exhaustive lists of specific techniques.

\section{Diagnostic competence}

Operationalized and criterion-oriented diagnostic is a central aspect of psychotherapy (Rief \& Stenzel, 2011) and, moreover, qualified diagnostic is the basic requirement for a disorder-specific treatment. Various models of therapeutic competences include diagnostic competence (Hatcher et al., 2013; Leith et al., 1989; Rodolfa et al., 2013). Interestingly, however, little is known about the actual relevance of diagnostic competence. In line with previous models (Kaslow, 2004) in our model, diagnostic competence refers to mastering diagnostic decisions based on classification systems (e.g. DSM-5, American Psychiatric Association, 2013) and to the evidence-based selection and use of assessment instruments and the psychometrically informed interpretation of psychological tests.

\section{Knowledge}

Many models of therapeutic competence include knowledge as a therapeutic competence (Fouad et al., 2009; Kaslow, 2004; Rodolfa et al., 2013; Roth \& Pilling, 2007). Consistent with the scientist-practitioner model, a therapist is characterized as being scientifically-minded (Kaslow, 2004, p. 776). Generally, knowledge is conceptualized as an understanding about biological, psychological and sociological models of mental disorders, their development, distribution and treatment, and in addition an understanding about statistics and research methods (Rodolfa et al., 2013; Strauss \& Kohl, 2009). Although knowledge is included in many models of therapeutic competence, there is surprisingly little systematic research on the importance of knowledge. As stated earlier, there are several instruments for assessing knowledge which have a number of limitations (e.g. EPPP, Rehm \& Lipkins, 2006). Yet, to the best of our knowledge, these instruments have not been investigated within the context of therapeutic competence.

In our model the component knowledge encompasses the knowledge of models of disorders and the psycho-biosocial processes involved in the development, maintenance and treatment of disorders. In addition, the therapist needs to have a thorough methodological expertise in order to be competent at making informed judgments of research findings.

\section{Case conceptualization}

As pre-requisite for treating clients, it is pivotal that the psychotherapist is able to organize and integrate assessment data in a meaningful way by taking into account available theoretical considerations and research findings in order to gain an understanding of the client's current symptomatology and behaviors (Porzelius, 2002). This so-called case conceptualization has been considered a core therapeutic competence which reflects theory, research and clinical practice (Kuyken, Fothergill, Musa, \& Chadwick, 2005; Sudak et al., 2003). Clearly, case con- 
ceptualization strongly depends on the therapeutic approach. At least within the context of CBT, the therapist is supposed to think like an empiricist (Newman, 2010, p. 14). Moreover, we believe that CBT-therapists should be competent at formulating a cognitive conceptualization, i.e. that clients' underlying assumptions about themselves and the world are identified (Cognitive Conzeptualization Diagram, Beck, 1995). For developing a conceptualization about an individual client, the therapist has to collect descriptive information about the client and then integrate them into hypotheses about causes, precipitant and maintenance (Eells, 1998). A case conceptualization is especially important for therapy outcome when clients' symptomatology is complex or when comorbidity is high (Kendjelic \& Eells, 2007). Interestingly, there is ongoing controversy as to whether case conceptualization is trainable (Sudak et al., 2003) or not (Dobson \& Shaw, 1993).

Our model includes case conceptualization as an essential therapeutic competence.

\section{The three level model of therapeutic competence and its practical use}

The main reason for developing Three Level Model of Therapeutic Competence was to create a measurement model that holds promise for developing instruments for assessing therapeutic competence from different perspectives (e.g., therapist, client), using self-report as well as observational measures, and relying on different measurement points (e.g., during session, before/after therapy). Dispositions can be assessed using standardized self-report questionnaires. For example, personality factors can be measured using personality questionnaires such as the NEO-FFI (Costa \& McCrae, 1985) and self-esteem can be measured by the Rosenberg Self-Esteem Scale (Rosenberg, 1989). Possibly, analytical thinking may be inferred from the performance in intelligence testing that specifically focuses on this intellectual ability. Accordingly, we postulate that most components at the levels of Basic Competences and Specific Competences are amenable to multi-informant (i.e. the different perspectives of therapist, client and observer) and multi-modal assessment (e.g. ratings, case vignettes, behavioral observations) and can potentially also be assessed during sessions.

\section{Conclusions}

In our view, the competency model as outlined here holds promise in that it provides a heuristic framework for developing and testing such assessment instruments, takes into account the issue of training and development of therapeutic competence, and its possible relationship to treatment outcome.

Crucial questions are whether the assumptions of the
Three Level Model of Therapeutic Competence concerning the influence of Dispositions and the differentiation between Basic and Specific Competences are empirically tenable. Furthermore, it needs to be tested if the model can indeed serve as theoretical basis for the development of multi-informant and multi-modal instruments to assess therapeutic competence.

\section{References}

Ackerman, S. J., \& Hilsenroth, M. J. (2001). A review of therapist characteristics and techniques negatively impacting the therapeutic alliance. Psychotherapy: Theory, Research, and Practice, 38, 171-185.

Ackerman, S. J., \& Hilsenroth, M. J. (2003). A review of therapist characteristics and techniques positively impacting the therapeutic alliance. Clinical Psychology Review, 23, 1-33. doi:10.1016/S0272-7358(02)00146-0

American Psychiatric Association. (2013). Diagnostic and statistical manual of mental disorders: DSM-5 (5th ed.). Washington, DC.

Antonuccio, D. O., Lewinsohn, P. M., \& Steinmetz, J. L. (1982). Identification of therapist differences in a group treatment for depression. Journal of Consulting and Clinical Psychology, 50, 433-435.

Aronson, E., Wilson, T. D., \& Akert, R. M. (2002). Social psychology (4th ed.). Upper Saddle River, NJ: Prentice Hall.

Aveline, M. (2005). The person of the therapist. Psychotherapy Research, 15, 155-164.

Baldwin, S. A., \& Imel, Z. E. (2013). Therapists Effects: Findings and methods. In M. J. Lambert (Ed.), Bergin and Garfield's handbook of psychotherapy and behavior change (6th ed., pp. 258-297). Hoboken, NJ: John Wiley \& Sons.

Bandura, A. (1977). Self-efficacy: toward a unifying theory of behavioral change. Psychological Review, 84, 191-215.

Barber, J. P., Sharpless, B. A., Klostermann, S., \& McCarthy, K. S. (2007). Assessing intervention competence and its relation to therapy outcome: A selected review derived from the outcome literature. Professional Psychology: Research and Practice, 38, 493-500. doi:10.1037/0735-7028.38.5.493

Barkham, M., Lutz, W., Lambert, M. J., \& Saxon, D. (2017). Therapist effects, effective therapists, and the law of variability. In L. G. Castonguay \& C. E. Hill (Eds.), How and why are some therapists better than others? Understanding therapist effects (pp. 13-36). Washington, DC: American Psychological Association.

Beck, J. S. (1995). Cognitive therapy: Basics and beyond. New York: Guilford Press.

Benjamin, L. S. (1974). Structural analysis of social behavior. Psychological Review, 81, 392-425.

Bennett-Levy, J. (2006). Therapist skills: a cognitive model of their acquisition and refinement. Behavioural and Cognitive Psychotherapy, 34, 57-78. doi:10.1017/S1352465805002420

Bergin, A. E. (1997). Neglect of the therapist and the human dimensions of change: a commentary. Clinical Psychology: Science and Practice, 4, 83-89. doi:10.1111/j.1468-2850.1997. tb00102.x

Beutler, L. E., Machado, P., \& Neufeldt, S. (1994). Therapist variables. In A. E. Bergin \& S. L. Garfield (Eds.), Handbook of psychotherapy and behavior change (4th ed., pp. 229269). New York: J. Wiley. 
Beutler, L. E., Malik, M., Alimohamed, S., Harwood, T. M., Talebi, H., Noble, S., \& Wong, E. (2004). Therapist variables. In M. J. Lambert (Ed.), Bergin and Garfield's handbook of psychotherapy and behavior change (5th ed., pp. 227-306). New York, NY: Wiley.

Carkhuff, R. R. (1969). Helping and human relations: A primer for lay and professional helpers; Vol. 1; Selection and Training. New York: Holt, Rinehart Winston.

Caspar, F., \& Eversmann, J. (2009). Was müssen Kandidatinnen und Kandidaten mitbringen, um einmal gute Therapeutinnen und Therapeuten zu werden? Psychotherapie, Psychosomatik, Medizinische Psychologie, 59, e1-e3. doi:10.1055/s-00291220357

Costa, P. T., \& McCrae, R. R. (1985). The NEO Personality Inventory, Psychological Assessment Resources, Inc., US.

Costanzo, M., \& Philpott, J. (1986). Predictors of therapeutic talent in aspiring clinicians: a multivariate analysis. Psychotherapy Research, 23, 362-369.

Dauber, H. (2006). Professionelle Selbstreflexion aus pädagogischer und psychoanalytischer Sicht. Schriftenreihe zur humanistischen Pädagogik und Psychologie. Bad Heilbrunn: Klinkhardt.

Dobson, K. S., \& Shaw, B. F. (1993). The training of cognitive therapists: what have we learned from treatment manuals. Psychotherapy: Theory, Research, Practice, Training, 30, 573-577.

Doering-Seipel, E., Schüler, P., \& Seipel, K. H. (2000). Wie beurteilen Ausbildungsteilnehmer Selbsterfahrung in der Verhaltenstherapie? In A.-R. Laireiter (Ed.), Selbsterfahrung in Psychotherapie und Verhaltenstherapie. Tübingen: dgvt-Verl.

Dryden, W., \& Feltham, C. (1994). Developing counsellor training. Developing counselling. London, Thousand Oaks: Sage.

Duckworth, A. L., Steen, T. A., \& Seligman, M. E. (2005). Positive psychology in clinical practice. Annual review of clinical psychology, 1, 629-651.

Eells, T. K. (1998). What's in a case formulation? Development and use of a content coding manual. Journal of Psychotherapy Practice and Research, 7, 144-153.

Elliott, R., Bohart, A. C., Watson, J. C., \& Greenberg, L. S. (2011). Empathy. In J. C. Norcross (Ed.), Psychotherapy relationships that work. Evidence-based responsiveness (2nd ed., pp. 132-152). New York: Oxford University Press. doi:10.1093/acprof:oso/9780199737208.003.0006

Elman, N. S., Illfelder-Kaye, J., \& Robiner, W. N. (2005). Professional development: training for professionalism as a foundation for competent practice in psychology. Professional Psychology: Research and Practice, 36, 367-375. doi:10.1037/0735-7028.36.4.367

Engvik, H. (1999). Therapeutic popularity and personality: Association between peer therapist nomination and the 'Big Five' personality factors. Scandinavian Journal of Psychology, 40, 261-267.

Epstein, R. M., \& Hundert, E. M. (2002). Defining and assessing professional competence. Journal of the American Medical Association, 228, 226-235.

Farber, B. A., \& Doolin, E. M. (2011). Positive regard. Psychotherapy (Chicago, Ill.), 48, 58-64. doi:10.1037/a0022141

Figley, C. R. (2002). Compassion fatigue: Psychotherapists' chronic lack of self care. Journal of Clinical Psychology, 58, 1433-1441. doi:10.1002/jclp.10090

Fouad, N. A., Grus, C. L., Hatcher, R. L., Kaslow, N. J., Hutchings, P. S., Madson, M. B.,... Crossman, R. E. (2009). Com- petency benchmarks: A model for understanding and measuring competence in professional psychology across training levels. Training and Education in Professional Psychology, 3, S5-S26.

Grawe, K. (2007). Neuropsychotherapy: How the neurosciences inform effective psychotherapy. Counseling and psychotherapy. Mahwah, NJ: Lawrence Erlbaum.

Grawe, K., Donati, R., \& Bernauer, F. (1994). Psychotherapie im Wandel: Von der Konfession zur Profession (3th ed.). Göttingen, Seattle: Hogrefe, Verlag für Psychologie.

Greenberg, L. S., Watson, J. C., Elliott, R., \& Bohart, A. C. (2001). Empathy. Psychotherapy: Theory, Research, Practice, Training, 38, 380-384.

Guy, J. D. (1987). The personal life of the psychotherapist. Wiley series on personality processes. New York, NY: Wiley.

Hatcher, R. L., Fouad, N. A., Grus, C. L., Campbell, L. F., McCutcheon, S. R., \& Leahy, K. L. (2013). Competency benchmarks: Practical steps toward a culture of competence. Training and Education in Professional Psychology, 7, 8491. doi:10.1037/a0029401

Hatcher, R. L., \& Lassiter, K. D. (2007). Initial training in professional psychology: The practicum competencies outline. Training and Education in Professional Psychology, 1, 4963. doi:10.1037/1931-3918.1.1.49

Heinonen, E., Knekt, P., Jääskeläinen, T., \& Lindfors, O. (2014). Therapists' professional and personal characteristics as predictors of outcome in long-term psychodynamic psychotherapy and psychoanalysis. European Psychiatry: the Journal of the Association of European Psychiatrists, 29, 265-274. doi:10.1016/j.eurpsy.2013.07.002

Henry, W. P., Schacht, T. E., \& Strupp, H. H. (1986). Structural analysis of social behavior: Application to a study of interpersonal process in differential psychotherapeutic outcome. Journal of Consulting and Clinical Psychology, 54, 27-31.

Henry, W. P., Schacht, T. E., \& Strupp, H. H. (1990). Patient and therapist introject, interpersonal process, and differential psychotherapy outcome. Journal of Consulting and Clinical Psychology, 58, 768-774. doi:10.1037/0022-006X.58.6.768

Hill, C. E. (2009). Helping skills: Facilitating exploration, insight, and action (3rd ed.). Washington, DC: American Psychological Association.

Hill, C. E., \& Lent, R. W. (2006). A narrative and meta-analytic review of helping skills training: Time to revive a dormant area of inquiry. Psychotherapy: Theory, Research, Practice, Training, 43(2), 154-172. doi:10.1037/0033-3204.43.2.154

Hill, C. E., Roffman, M., Stahl, J., Friedman, S., Hummel, A., \& Wallace, C. (2008). Helping skills training for undergraduates: Outcomes and prediction of outcomes. Journal of Counseling Psychology, 55, 359-370. doi:10.1037/0022-0167.55.3.359

Horvath, A. O., Del Re, A. C., Flückiger, C., \& Symonds, D. (2011). Alliance in individual psychotherapy. Psychotherapy (Chicago, Ill.), 48, 9-16. doi:10.1037/a0022186

James, I. A., Blackburn, I.-M., Milne, D. L., \& Reichfelt, F. K. (2001). Moderators of trainee therapists' competence in cognitive therapy. British Journal of Clinical Psychology, 40, 131-141.

Kanfer, F. H. (2006). Selbstmanagement-Therapie: Ein Lehrbuch für die Klinische Praxis. Berlin: Springer.

Kanfer, F. H., \& Schefft, B. K. (1988). Guiding the process of therapeutic change. Champaign, Ill: Research Press.

Kaslow, N. J. (2004). Competencies in Professional Psychology. American Psychologist, 59, 774-781.

Kaslow, N. J., Borden, K. A., Collins, F. L., Forrest, L., Illfelder- 
Kaye, J., Nelson, P. D.,... Willmuth, M. E. (2004). Competencies conference: future directions in education and credentialing in professional psychology. Journal of Clinical Psychology, 60, 699-712. doi:10.1002/jclp.20016

Kendjelic, E. M., \& Eells, T. D. (2007). Generic psychotherapy case formulation training improves formulation quality. Psychotherapy: Theory, Research, Practice, Training, 44, 6677. doi:10.1037/0033-3204.44.1.66

Kolden, G. G., Klein, M. H., Wang, C.-C., \& Austin, S. B. (2011). Congruence/genuineness. Psychotherapy (Chicago, Ill.), 48, 65-71. doi:10.1037/a0022064

Kuyken, W., Fothergill, C., Musa, M., \& Chadwick, P. (2005). The reliability and quality of cognitive case formulation. Behaviour research and therapy, 43, 1187-1201. doi: 10.1016/j.brat.2004.08.007

Langer, A., \& Frank, R. (1999). Erfassung verhaltenstherapeutischer Kompetenzen durch direkte Verhaltensbeobachtung:: Entwicklung eines Beobachtungsbogens für eine kriterienorientierte Supervision. Verhaltenstherapie, 9, 30-37.

Larson, L. M., \& Daniels, J. A. (1998). Review of the Counseling Self-Efficacy Literature. The Counseling Psychologist, 26, 179-218. doi:10.1177/0011000098262001

Leith, W., McNiece, E. M., \& Fusilier, B. B. (1989). Handbook of supervision: A cognitive behavioral system. Boston: Little, Brown.

Lemma, A., Roth, A. D., \& Pilling, S. (2008). The competences required to deliver effective Psychoanalytic/ Psychodynamic Therapy. Available from: https://www.ucl.ac.uk/pals/research/cehp/research-groups/core/competence-frameworks/Psychoanalytic-Psychodynamic-Therapy

Lent, R. W., Hill, C. E., \& Hoffman, M. A. (2003). Development and validation of the Counselor Activity Self-Efficacy Scales. Journal of Counseling Psychology, 50, 97-108. doi:10.1037/0022-0167.50.1.97

Loo, C. (1979). Measures for predicting therapeutic skill and the effects of training. Psychotherapy: Theory, Research, and Practice, 16, 460-466.

Mahoney, M. (1997). Psychotherapists' personal problems and self-care patterns. Professional Psychology: Research and Practice, 28, 14-16.

Mallinckrodt, B. (2000). Attachment, social competencies, social support, and interpersonal process in psychotherapy. Psychotherapy Research, 10, 239-266. doi:10.1093/ptr/10.3.239

Martin, D. J., Garske, J. P., \& Davis, M. K. (2000). Relation of the therapeutic alliance with outcome and other variables: a meta-analytic review. Journal of Consulting and Clinical Psychology, 68, 438-450.

McCrae, R. R., \& John, O. P. (1992). An introduction to the fivefactor model and its applications. Journal of Personality, 60, 175-215. doi:10.1111/j.1467-6494.1992.tb00970.x

Milne, D., Claydon, T., Blackburn, I.-M., James, I., \& Sheikh, A. (2001). Rational for a new measure of competence in therapy. Behavioural and Cognitive Psychotherapy, 29, 21-33.

Newman, C. F. (2010). Competency in conducting cognitivebehavioral therapy: foundational, functional, and supervisory aspects. Psychotherapy: Theory, Research, Practice, Training, 47, 12-19. doi:10.1037/a0018849

Nissen-Lie, H. A., Monsen, J. T., Ulleberg, P., \& Rønnestad, M. H. (2013). Psychotherapists' self-reports of their interpersonal functioning and difficulties in practice as predictors of patient outcome. Psychotherapy Research, 23, 86-104. doi:10.1080/10503307.2012.735775

Norcross, J. (2000). Psychotherapists self-care: practitioner- tested, research-informed strategies. Professional Psychology: Research and Practice, 31, 710-713.

Norcross, J. C., \& Guy, J. D. (2007). Leaving it at the office: A guide to psychotherapist self-care. New York: Guilford Press.

Orlinsky, D. E., \& Howard, K. I. (1987). A generic model of psychotherapy. Journal of Integrative \& Eclectic Psychotherapy, 6, 6-27.

Porzelius, K. L. (2002). Overview. In M. Hersen \& L. K. Porzelius (Eds.), Diagnosis, Conceptualization, and Treatment Planning for Adults. A step-by-step guide (pp. 3-12). Mahwah, NJ: Lawrence Erlbaum Associates.

Purton, C. (1991). Selection and assessment in counsellor training courses. In W. Dryden \& B. Thorne (Eds.), Counselling in action. Training and supervision for counselling in action (pp. 33-48). London, Newbury Park, CA: Sage.

Rehm, L. P., \& Lipkins, R. H. (2006). The examination for professional practice in psychology. In T. J. Vaughn (Ed.), Psychology licensure and certification. What students need to know (1st ed., pp. 39-53). Washington, DC: American Psychological Association.

Rief, W., \& Stenzel, N. (2011). Diagnostik und Klassifikation. In M. Berking \& W. Rief (Eds.), Springer-Lehrbuch. Klinische Psychologie und Psychotherapie für Bachelor (1st ed., pp. 9-17). Berlin: Springer.

Rodolfa, E., Bent, R., Eisman, E., Nelson, P., Rehm, L., \& Ritchie, P. (2005). A Cube Model for Competency Development: Implications for Psychology Educators and Regulators. Professional Psychology: Research and Practice, 36(4), 347-354. doi:10.1037/0735-7028.36.4.347

Rodolfa, E., Greenberg, S., Hunsley, J., Smith-Zoeller, M., Cox, D., Sammons, M.,...Spivak, H. (2013). A competency model for the practice of psychology. Training and Education in Professional Psychology, 7, 71-83. doi:10.1037/ a0032415

Rogers, C. R. (1957). The necessary and sufficient conditions of therapeutic personality change. Journal of Consulting Psychology, 21, 95-103. doi:10.1037/h0045357

Rønnestad, M. H., \& Skovholt, T. M. (2013). The developing practitioner: Growth and stagnation of therapists and counselors. New York, NY: Routledge.

Rosenberg, M. (1989). Society and the adolescent self-image (Rev. ed., 1st Wesleyan ed). Middletown, Conn: Wesleyan University Press.

Roth, A. D., \& Pilling, S. (2007). The competences required to deliver effective cognitive and behavioural therapy for people with depression and with anxiety disorders. Available from: http://www.ucl.ac.uk/clinicalpsychology/CORE/CBT_Competences/CBT_Competence_List.pdf

Rubin, N. J., Bebeau, M., Leigh, I. W., Lichtenberg, J. W., Nelson, P. D., Portnoy, S.,... Kaslow, N. J. (2007). The competency movement within psychology: An historical perspective. Professional Psychology: Research and Practice, 38, 452-462. doi:10.1037/0735-7028.38.5.452

Schaffer, J. B., Rodolfa, E. R., Hatcher, R. L., \& Fouad, N. A. (2013). Professional psychology competency initiatives: Reflections, contrasts, and recommendations for the next steps. Training and Education in Professional Psychology, 7, 9298. doi:10.1037/a0032038

Schmelzer, D. (1997). Verhaltenstherapeutische Supervision: Theorie und Praxis. Göttingen, Seattle: Hogrefe-Verlag für Psychologie.

Sharpless, B., \& Barber, J. P. (2009). A Conceptual and empirical review of the meaning, measurement, development, and 
teaching of intervention competence in clinical psychology. Clin Psychol Rev, 29, 1-18.

Skovholt, T. M. (2012). Becoming a therapist: On the path to mastery. Hoboken, NJ: John Wiley and Sons.

Skovholt, T. M., \& Rønnestad, M. H. (1992). Themes in therapist and counselor development. Journal of Counseling \& Development, 70, 505-515.

Strauss, B., \& Kohl, S. (2009). Themen der Ausbildungsforschung in der Psychotherapie. Psychotherapeut, 54, 411426. doi:10.1007/s00278-009-0710-6

Sudak, D. M., Beck, J. S., \& Wright, J. W. (2003). Cognitive behavioral therapy: a blueprint for attaining and assessing psychiatry resident competency. Academic Psychiatry, 27, 154-159.

Thwaites, R., \& Bennett-Levy, J. (2007). Conceptualizing empathy in cognitive behaviour therapy: making the implicit explicit. Behavioural and Cognitive Psychotherapy, 35, 591612. doi:10.1017/S1352465807003785

Wampold, B. E. (2001). The great psychotherapy debate:
Models, methods, and findings. Mahwah, NJ: L. Erlbaum. Wampold, B. E., Baldwin, S. A., Grosse Holtforth, M., \& Imel, Z. E. (2017). What characterizes effective therapists? In L. G. Castonguay \& C. E. Hill (Eds.), How and why are some therapists better than others? Understanding therapist effects (pp. 37-53). Washington, DC: American Psychological Association.

Williams, K. E., \& Chambless, D. L. (1990). The relationship between therapist characteristics and outcome of in vivo exposure treatment for agoraphobia. Behavior Therapy, 21, 111-116.

Willutzki, U., \& Laireiter, A. (2005). Ausbildung in Verhaltenstherapie-Was ist ein guter (Verhaltens-) therapeut und wie soll Ausbildung gestaltet sein? In Lairaiter \& Willutzki (Ed.), Ausbildung in Verhaltenstherapie (pp. 21-49).

Wise, E. H., Hersh, M. A., \& Gibson, C. M. (2012). Ethics, selfcare and well-being for psychologists: Reenvisioning the stress-distress continuum. Professional Psychology: Research and Practice, 43, 487-494. doi:10.1037/a002944 